\title{
Corrupción, fiscalización y "camaleonismo político" durante la dictadura de Primo de Rivera en la provincia de Alicante $^{1}$
}

\section{Corruption, Auditing and camaleonismo politico during the Primo de Rivera's dictatorship in Alicante}

\author{
JONATAN POVEDA JOVER \\ Universidad de Alicante \\ jonatanpoveda@ua.es
}

Resumen: La imposición de la dictadura de Primo de Rivera tuvo como fundamento discursivo el saneamiento y regeneración de la vida política del país. Este propósito político, que explica, en parte, la pasividad y falta de oposición inicial a la Dictadura, se plasmó a través de una labor inicial de vigilancia y fiscalización de las estructuras políticas y administrativas del país. Como en el conjunto del Estado, la provincia de Alicante se vio sacudida por una fiebre anticaciquil y anticorruptiva que se fue diluyendo conforme el régimen se institucionalizaba y precisaba de la connivencia de los sectores más influyentes del territorio. Este trabajo trata de revisar las peculiaridades de la política anticaciquil y fiscalizadora desarrollada por la Dictadura en Alicante. Para ello, analizaremos la actuación de los gobernadores, de los delegados gubernativos, el papel activo de la prensa y toda la pléyade de disposiciones normativas y sustituciones políticas dirigidas a constituir una "administración pública honesta" (en palabras de los primorriveristas). Finalmente, haremos un balance general de esa estrategia política en Alicante: si se hizo efectiva la depuración de responsabilidades, si se avanzó hacía una mayor integridad administrativa y si se consiguió reducir la influencia de los grupos de poder territoriales.

Palabras clave: corrupción, fiscalización, dictadura, Primo de Rivera, Alicante.

Abstract: The imposition of Primo de Rivera dictatorship had as its fundamental objective the sanitation and regeneration of the political life of the country. This political proposal, which explained somehow the apathy and lack of initial opposition against the dictatorship, was reflected by an initial task of surveillance and auditing of the political and administrative structures of the country. As in the rest of Spain, the province of Alicante experienced an anti-corruption and anticaciquil fever that was reduced at the same time the regime promoted its process of institutionalization and needed the connivance of the

\footnotetext{
${ }^{1}$ El autor de este trabajo cuenta con una ayuda para la contratación de personal investigador de carácter predoctoral concedida por la Generalitat Valenciana en 2015.
}

Recibido: 18 de octubre de 2017; aceptado: 8 de enero de 2018; publicado: 27 de septiembre de 2018.

Revista Historia Autónoma, 13 (2018), pp. 125-143

DOI: https://doi.org/10.15366/rha2018.13.007 
most influential segments of the territory. This paper tries to revise the peculiarities of the anticaciquil and audit policy developed by the Dictatorship in Alicante. We will analyse the action of the Civil Government of Alicante, the active press behaviour and all the laws directed towards building an "honest public administration" (in words of the primorriveristas). Finally, we will make a general balance about this political strategy in Alicante: Was it possible to clarify responsibilities? Did the regime achieve an enhanced administrative integrity? Was it possible to reduce the influence of the territorial power groups?

Keywords: Corruption, Auditing, Dictatorship, Primo de Rivera, Alicante. 
1. Consideraciones iniciales

En la madrugada del 13 de septiembre, tras haber advertido al rey del inminente levantamiento ${ }^{2}$, el capitán general de Cataluña, Miguel Primo de Rivera, asumió el poder del país a través de un pronunciamiento clásico. Hacía 50 años que los militares no intervenían directamente en la política, parecía que esa vieja tradición decimonónica, la de presentarse como salvadores de la patria, había quedado para la historia al lograr mediante la Restauración un sistema estable en el cual los dirigentes políticos y sus clientelas encontraban en las Cortes y el Monarca, y no en los cuarteles, la solución a los pleitos políticos, ambiciones e intereses ${ }^{3}$.

Los factores condicionantes del golpe fueron diversos 4 : la crisis económica posbélica, el ascenso de la conflictividad social, el problema de las responsabilidades y la inoperancia del régimen de la Restauración, con sus vicios inherentes, contribuyeron a que el ejército, imbuido desde principios de siglo por un regeneracionismo de carácter autoritario ${ }^{5}$, efectuase un golpe que la ciudadanía recibió entre un sentimiento de desconcierto y expectación.

El pronunciamiento militar vino acompañado de un discurso modernizador y regenerador de las estructuras políticas, económicas y administrativas del país. Conscientes de la ilegitimidad del régimen, la Dictadura se apresuró a construir un discurso y un proyecto anticaciquil y anticorruptivo, no original ${ }^{6}$, que señalaba al Parlamentarismo, y en concreto a la Restauración, como un sistema oligárquico, corrupto y fraudulento incapaz de solucionar los problemas del país ${ }^{7}$.

En el manifiesto del 13 de septiembre el Dictador justificaba el golpe como necesario e inaplazable (ante la ruina del país) y volvía a colocar a los militares como guardianes de la nación. Sobre los profesionales de la política, aquellos que participaron y se beneficiaron de los entramados torticeros de la Restauración, recayeron todas las responsabilidades. Desde comienzos del reinado de Alfonso XIII los partidos dinásticos entraron en un proceso de crisis, de descomposición en familias políticas, que terminó por alterar el turno y hacer más evidente el sustrato caciquil que sustentaba el montaje político de la Restauración. La crisis de posguerra no hizo más que agravar la situación al generar una inestabilidad gubernamental que

\footnotetext{
${ }^{2}$ Moreno-Luzón, Javier, Modernizing the nation. Spain during the Reign of Alfonso XIII, 1902-1931, Sussex, Sussex Academic Press, 2012, p. 139.

${ }^{3}$ Varela Ortega, José, El poder de la influencia. Geografía del caciquismo en España (1875-1923), Madrid, Marcial Pons, 2001, p. 12.

${ }^{4}$ González Calbet, María Teresa, La Dictadura de Primo de Rivera: el Directorio Militar, Madrid, Arquero, 1987, pp. 19-53.

${ }_{5}^{5}$ Quiroga Fernández de Soto, Alejandro, Haciendo españoles. La nacionalización de las masas en la Dictadura de Primo de Rivera (1923-1930), Madrid, Centro de Estudios Políticos y Constitucionales, 2008, p. 89.

${ }^{6}$ Desde principios de siglo intelectuales como Joaquín Costa, Ángel Ganivet y Ortega y Gasset habían desarrollado un discurso crítico contra los vicios de la Restauración.

${ }^{7}$ La solución dictatorial se justificó mesiánicamente como la única alternativa para "proscribir a los políticos corruptos y al parlamentarismo estéril". Ben-Ami, Shlomo, "Hacia una comprensión de la Dictadura de Primo de Rivera”, en Revista del Departamento de Derecho Político, 6 (1980), p. 120.
} 
incapacitó la resolución de los problemas que afectaban al país. Ello dio lugar a una sensación de inacción e ineficacia que tendió a aumentar las críticas hacia el sistema y a dejar en evidencia el burocratismo y la corrupción política ${ }^{8}$.

La provincia de Alicante no quedó al margen de esa dinámica. Si en el resto del país los mecanismos de turno político fallaban desde la primera década del siglo xx, en la provincia de Alicante se fue fraguando una hegemonía del partido liberal que terminó por controlar, a través de sus cacicatos, numerosas comarcas ${ }^{9}$. Si a nivel estatal era difícil la distinción entre conservadores y liberales, en las sociedades de provincia la línea divisoria tendía a translucirse, pudiéndose rastrear, constantes casos de transfuguismo más fundamentados en intereses individuales que ideológicos ${ }^{10}$.

El caciquismo en la provincia de Alicante se ejerció mediante un sistema de relaciones que impregnó la vida del territorio. Este sistema, que se sirvió de diversos mecanismos como la colocación laboral, deducciones fiscales o favores personales, se hacía más evidente en el periodo de elecciones, cuando el cacique debía demostrar su influencia.

Toda esa serie de mecanismos embrutecedores de la política fueron deslegitimando a un régimen que se granjeó, con sus múltiples crisis abiertas, una gran cantidad de oponentes. Desde 1918 la abstención continuada y el rechazo a los partidos dinásticos en la provincia de Alicante da muestra de la indiferencia y la oposición de amplios sectores de la ciudadanía. En los años previos al golpe la prensa alicantina recrudeció sus editoriales señalando los vicios del caciquismo y el entramado corrupto que sustentaba la Restauración. A esta reprobación se unieron los crecientes partidos marginados por el sistema y una nueva burguesía, industrial y mercantil, que trataba de abrirse camino frente al bloque social agrario y financiero que había controlado la Restauración ${ }^{11}$.

\section{Fiebre fiscalizadora: alcance}

En las comarcas alicantinas el golpe militar vino acompañado de un sentimiento de desconcierto y expectación. La confusión que mostró la prensa y la sociedad alicantina durante la jornada del 14 de septiembre quedó despejada tras una serie de telegramas que ordenaban a

\footnotetext{
${ }^{8}$ Tamames Gómez, Ramón, Ni Mussolini ni Franco: la dictadura de Primo de Rivera y su tiempo, Barcelona, Planeta, 2008, pp. 45-47.

${ }^{9}$ Forner Muñoz, Salvador y Mariano García Andreu, Cuneros y caciques. Alicante, Patronato Municipal del V Centenario de la Ciudad de Alicante, 1990, pp. 215-223.

${ }^{10}$ Forner Muñoz, Salvador, “La Dictadura y la Segunda República”, en Uroz Sáez, José, Historia de la provincia de Alicante. Tomo VI, Murcia, Ediciones Mediterráneo, 1985, pp. 51-52.

${ }^{11}$ Gómez-Navarro fundamentó la crisis de la Restauración como el resultado de los desequilibrios producidos por una sociedad en vías de modernización y un régimen político reticente a las transformaciones necesarias. GómezNavarro, José Luis, El régimen de Primo de Rivera: reyes, dictadura y dictadores, Madrid, Cátedra, 1991.
} 
Ricardo Aparicio, gobernador civil de Alicante, que cediese el mando de la provincia al general Cristino Bermúdez de Castro ${ }^{12}$. En Alicante, el golpe triunfó sin demasiados contratiempos, muy pocos se pronunciaron por el régimen constitucional saliente. En las jornadas posteriores al pronunciamiento la prensa alicantina mostró, salvo contadas excepciones, un sentimiento de complacencia cuasi unánime con el nuevo régimen ${ }^{13}$. Como en el resto del país, la Cámara de Comercio, la Cámara Oficial de la Propiedad Urbana y otros organismos representativos de la burguesía alicantina recibieron con entusiasmo al Dictador ${ }^{14}$. También considerables sectores obreros y de clases medias reconocieron inicialmente a un régimen que se postuló como provisional (noventa días) y reparador de las caducas y corruptas prácticas de la Restauración. Su cruzada contra el caciquismo y los mecanismos ilícitos de la vieja política le permitieron un respaldo inicial pese haber alcanzado el poder de forma ilegítima.

Los primorriveristas, conocedores del desprestigio y rechazo generalizado hacia el régimen de la Restauración, explotaron desde un primer momento un discurso punitivo e inquisitivo contra los representantes de la antigua política. La idea, más teórica que real, era establecer un paréntesis curativo en el cual se sanearía el cuerpo social y político de la nación, para devolverlo posteriormente a un régimen de garantías constitucionales. Este discurso apoyado desde el 15 de septiembre, una vez decretada la censura de prensa, en la complacencia y arenga de las principales editoriales alicantinas, permitió la pronta aceptación por un importante contingente de la ciudadanía.

La labor del Ejecutivo durante los primeros meses del Directorio Militar se centró en establecer un gobierno de autoridad y eficacia que, inspirado en el conservadurismo social y regeneracionismo de principios de siglo, trató de solucionar los problemas existentes a través de un reguero de reales decretos. Como señaló Gómez-Navarro, "se trataba de liberar el país de la vieja política y de los viejos políticos, destruyendo todo el aparato viciado de la Restauración"15.

Las medidas represivas y de fiscalización aprobadas durante los primeros meses de la Dictadura vinieron acompañadas de una militarización del orden público que ejerció su represión de forma selectiva, funcional e indiscutida. La primera de las disposiciones tendentes a militarizar el orden e iniciar la fiscalización de las regiones de España fue el decreto de sustitución de Gobernadores Civiles por Militares del 20 de septiembre. El propósito era claro: si se quería descuajar el caciquismo, el cual hundía sus raíces en las sociedades de provincia, eran necesarias autoridades desvinculadas del territorio que actuasen como brazos ejecutores del Dictador.

\footnotetext{
${ }^{12}$ Archivo Histórico Nacional [en adelante, AHN], Ministerio de Interior, Serie A, leg. 37/1.

${ }^{13}$ Moreno Sáez, Francisco, La prensa en la ciudad de Alicante durante la dictadura de Primo de Rivera, Alicante, Instituto de Cultura Juan Gil-Albert, 1995, pp. 11-12.

${ }^{14}$ Pérez Ortiz, Juan Francisco, La Provincia de Alicante durante la Dictadura de Primo de Rivera: evolución política, Memoria de licenciatura, Universidad de Alicante, 1990, pp. 26-27.

${ }^{15}$ Gómez Navarro, José Luis, El régimen ... op. cit., p. 338.
} 
En la provincia de Alicante ese cargo lo detentó el general Cristino Bermúdez de Castro quien, a través del ejercicio imperativo de sus funciones, se convirtió en el alter ego provincial del dictador ${ }^{16}$. Durante las primeras semanas, antes del decreto del 20 de octubre que ordenaba la creación de los delegados gubernativos, su protagonismo en la provincia fue exclusivo. En sus manos se concentró todo el poder fiscalizador del territorio, el cual se hizo efectivo a través de una multitud de ordenanzas e inspecciones que trataron, por un lado, de combatir las "covachuelas del caciquismo" $" 17$, por otro, de publicitar una imagen enérgica y de trabajo sin límite que acercase el Directorio a la ciudadanía. En este punto, las estructuras del régimen a nivel provincial contaron desde un primer momento con la buena disposición de la prensa en la confección de la campaña propagandista. Las esperanzas iniciales en el proyecto regeneracionista, el decreto de censura de prensa y control de la mayoría de las editoriales por la burguesía alicantina favoreció la imagen complaciente de un importante número de diarios. Alguno de los casos más significativos, que permite anteceder la tesis del camaleonismo político que después analizaremos, será el del Correo y el Día. El primero de ellos, propiedad de Florentino Elizaicin, político conservador durante el quinquenio previo a la dictadura, criticó inicialmente la censura de prensa, para pasar a ser nombrado en 1927 censor de la prensa provincial $^{18}$ y en 1930 alcalde de la ciudad de Alicante. Otro caso significativo será el del periódico liberal el Día, propiedad del cacique Alfonso de Rojas (enormemente señalado por la fiebre fiscalizadora), que tras su renuncia al frente de la redacción, paso a ser uno de los lisonjeros del nuevo régimen.

La prensa periódica, junto con los fondos de Gobierno Civil del Archivo de la Diputación de Alicante y del Archivo Histórico Nacional, nos permiten conocer con amplitud la labor de inspección desarrollada desde el gobierno civil de Alicante. Era evidente que si la Dictadura quería sanear la administración, aplicar responsabilidades políticas y desarmar los antiguos lazos de poder, iba a necesitar toda una pléyade de disposiciones normativas, sustituciones y nuevos cargos que garantizasen el control de hasta el más reducido de los municipios. Bermúdez de Castro podía fiscalizar las instituciones más próximas a la capital: la cárcel del partido, la beneficencia o el Hospital Civil; pero sin un cuerpo de apoyo a nivel municipal y comarcal, que espiase e hiciese de nexo entre el municipio y el gobernador, la labor quedaba inconclusa.

El 20 de octubre de 1923 se creaba una nueva rueda en la administración, los delegados gubernativos. Este cuerpo de oficiales militares deslocalizados ${ }^{19}$, que se fue reduciendo a lo largo de la Dictadura, nacía con la voluntad de crear una "nueva patria" y hacer efectiva, en

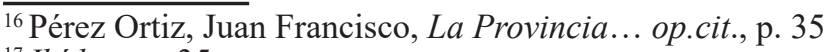

${ }^{17}$ Ibídem, p. 35.

18 "Orden del día", en Diario de Alicante, 13 de enero de 1927.

${ }^{19}$ Según Calvo Sotelo, para este cuerpo de inspección y observancia de la vida municipal se seleccionó a oficiales sin contacto previo con sus partidos judiciales de destino para evitar estar "contaminados por el enrarecido ambiente político pueblerino". Calvo Sotelo, José, Mis servicios al Estado. Seis años de gestión, Madrid, Instituto de Estudios de la Administración Local, 1972, pp. 26-29
} 
todos los rincones del país, la presencia del $\operatorname{poder}^{20}$. El 30 de septiembre se aprobaba por Real Decreto la disolución de los ayuntamientos y la sustitución de sus corporaciones por las Juntas de Vocales Asociado, doce días después, el Directorio aprobaba el decreto de incompatibilidades políticas. En este periodo de descomposición de la estructura política del país, el Ministerio de Gobernación vio necesaria la creación de un enlace, entre el municipio y los gobiernos civiles, que tutelase, vigilase y diese sensación de autoridad a nivel local. A partir del nombramiento de los primeros delegados puede rastrearse en la documentación primaria y en la prensa la eclosión de una fiebre de delaciones y procesos de fiscalización utilizados de forma proselitista a través de una imagen de firmeza, escarnio y lucha contra la ilegalidad.

La administración provincial y los ayuntamientos acapararon desde el primer momento la atención del gobierno civil con un aluvión de procedimientos de inspección y fiscalización. Se iniciaron visitas de inspección a los ayuntamientos de la provincia, se arquearon las cuentas municipales en busca de irregularidades ${ }^{21}$ y se presionó a los nuevos consistorios para que saldasen sus deudas y racionalizasen sus finanzas.

El gobierno provincial no estuvo solo al frente de esa tarea, ya que la prensa colaboró activamente señalando a caciques y presuntos delincuentes políticos. En el punto de mira de los rotativos estuvieron los grandes caciques de la provincia: Salvador $\mathrm{Canals}^{22}$, cacique conservador y Consejero de la Compañía Transmediterránea y de Ferrocarriles Estratégicos; Alfonso de Rojas, cacique liberal, el cual abandonó Alicante para alejarse del punto de mira ${ }^{23}$; y Rafael Beltrán Ausó24, cacique liberal de la capital, investigado por el decreto de incompatibilidades por simultanear sus funciones políticas con el cargo de consejero de Distribución Eléctrica Alicantina.

A finales de octubre un Real Decreto capacitaba a los ciudadanos para personarse en las sesiones municipales y exponer sus quejas y reclamaciones ${ }^{25}$. Esta medida que permitía la participación de los ciudadanos en "la regeneración del país" se complementaba con las arengas hechas desde el Gobierno Civil para que los ciudadanos denunciasen cualquier acto considerado ilícito $^{26}$. Estas disposiciones vinieron acompañadas de una multitud de denuncias y acusaciones a políticos, empleados públicos ${ }^{27}$, empresarios, prostitutas, etc. El Ayuntamiento de la capital, en el cual se descubrieron diversas irregularidades administrativas, fue utilizado como ente ejemplarizante para el resto de consistorios provinciales. En el ayuntamiento de Alicante se

\footnotetext{
${ }^{20}$ Pérez Ortiz, Juan Francisco, "Los delegados gubernativos militares (de la provincia de Alicante) durante la dictadura de Primo de Rivera", en Espacio, tiempo y forma. Serie V: Historia Contemporánea, 3 (1990), pp. 395396.

${ }^{21}$ Archivo de la Diputación de Alicante [en adelante, ADA], GE-16949-11. Este legajo nos permite rastrear la inspección fiscal y presupuestaria dirigida por el delegado gubernativo de Villena.

22 "Castigo para todos. El cacique conservador", en El Luchador, 15 de diciembre de 1923.

${ }^{23}$ Forner Muñoz, Salvador y Mariano García Andreu, Caciques... op. cit., p. 35.

24 “El Sr. Beltrán y la fábrica de Gas", en El Tercio, 25 de noviembre de 1923.

${ }^{25}$ Gaceta de Madrid, 30 de octubre de 1923.

${ }^{26}$ El Luchador, 27 de octubre de 1923.

${ }^{27}$ El delegado gubernativo de Alcoy recibe una denuncia de las irregularidades cometidas por diversos funcionarios técnicos de Alcoy. ADA, GE-16910-3.
} 
abrió un expediente de denuncias que se extendió hasta 1928. Es significativo observar cómo a mediados de 1924, cuando empieza a producirse la entente cordial entre los representantes de la Dictadura y la antigua política ${ }^{28}$, se redujo drásticamente el número de denuncias ${ }^{29}$. Entre las más significativas tenemos la reapertura de un sumario instruido en 1921 contra el cacique Alfonso de Rojas o la denuncia de un vecino contra el exconcejal conservador, Florentino de Elizaicin, por apropiarse de un terreno público.

En los distintos municipios de la provincia tal vez sea donde mejor se aprecian los procedimientos de descuaje y fiscalización de la antigua administración. Fruto de las medidas adoptadas y las inspecciones efectuadas se produjo una considerable cantidad de detenciones y procesos a alcaldes, concejales, secretarios, recaudadores de arbitrios, etc. ${ }^{30}$. Los casos más significativos se sucedieron entre octubre de 1923 y marzo de 1924. El 27 de octubre el Luchador informaba que Juan Crespo García, recaudador de impuestos de Benisa, había sido detenido por estafa y malversación. En la misma columna se informaba que el alcalde, secretario, exalcalde y exdepositario de Callosa del Segura habían ingresado en la cárcel de Dolores $^{31}$. El 29 de noviembre se comunicaba que habían sido detenidos en Salinas "seis hombres de postín [...] que no hace mucho se desacharraban hablando de su fe en el orden y el respeto de las cosas establecidas" ${ }^{\prime 32}$. Fue muy habitual tras el golpe que las fuerzas vivas de la provincia apelasen a las bondades del Directorio. Entre los casos más mediáticos y llamativos ${ }^{33}$ destaca la detención en la Cárcel Militar de Alicante de nueve concejales, un exalcalde, Manuel Canales, y un exdiputado, José Martínez Arenas ${ }^{34}$, de la ciudad de Orihuela (las detenciones se fundamentaban en la supresión ilegal de servicios prioritarios para el municipio) ${ }^{35}$.

Sin lugar a dudas, uno de los procesos más ejemplarizantes contra la vieja política, el cual trató de mostrar que el Directorio fiscalizaría todos los estratos del poder, fue la causa abierta contra Ricardo Aparicio, Gobernador Civil de Alicante hasta el 14 de septiembre de 1923. El sumario comenzó a instruirse el 31 de octubre de 1923 por el Juzgado Militar de Alicante. Se le acusaba de haber malversado los fondos que las Compañías de Ferrocarriles debían destinar anualmente a la beneficencia provincial. Al parecer cobró 8162,42 pesetas de estas compañías, solo pudiendo justificar documentalmente haber entregado 4832 pesetas a la beneficencia. El

\footnotetext{
${ }^{28}$ Muñoz Jofre, Jaume, La España corrupta. Breve historia de la corrupción (de la Restauración a nuestros días, 1875-2016), Granada, Comares, 2016, p. 49.

${ }^{29}$ Archivo Municipal de Alicante [en adelante, AMA], leg. 1918-89-32.

${ }^{30}$ ADA, 16946-1. El recaudador de impuestos de Penáguila, José Bonet Castelló, fue acusado de apropiación de fondos y cesado.

31 "Sigue la Racia. Más detenidos", en El Luchador, 27 de octubre 1923.

${ }^{32}$ Según las informaciones del Luchador y El Periódico de Alicante del 29 de noviembre de 1923, en esta localidad fueron detenidos cinco exalcaldes. Detenciones que se sumaban a las de Altea, Sax, Bañeres (ADA, 16910-3), Agost y otros pueblos de la provincia.

${ }_{33}^{3}$ Uno de los casos más disonantes, que demuestra la reiterada extracción de bienes del Estado en beneficio propio, fue la denuncia contra el exalcalde de Benifallim, Enrique Aznar, por venderle a su hermana el patio de la casa consistorial. ADA, GE-16910-3.

${ }^{34}$ José Martínez Arenas perteneció, primero, a la clientela del cacique conservador oriolano Marqués de Rafal. Cuando este perdió la hegemonía del territorio, no dudó en vincularse al nuevo cacique liberal Ruiz Valarino.

35 "De Orihuela. Son sumariados varios concejales y traídos al Castillo de Santa Bárbara", en El Luchador, 8 de octubre de 1923 .
} 
sumario, que finalmente se trasladó a una sala de lo criminal del Tribunal Supremo, terminó considerando (el 22 de abril de 1924) al acusado culpable, instruyéndose un embargo de sus bienes por valor 8000 pesetas y libertad condicional bajo 3000 pesetas de fianza ${ }^{36}$. Esta causa tuvo que tener un amplio eco popular, pues se trataba, por su significación, del Santiago Alba alicantino. Finalmente, en noviembre de 1924, el Tribunal Supremo decretaba el indulto total a Ricardo Aparicio, acogiéndose este al artículo 2 del RD de 4 de julio de amnistía e indulto general ${ }^{37}$.

El decreto de indulto y amnistía general demostraba legislativamente que la fiebre punitiva que se había instaurado en el país fue más teórica que real. Si seguimos el rastro de aquellas personalidades detenidas e investigadas, podemos observar que pronto se las dejó en libertad ${ }^{38}$ o se beneficiaron de la amnistía penal. La gran mayoría de procesados solo sufrieron multas y encarcelamientos de poca duración ${ }^{39}$. En vano fue la destrucción de archivos municipales (en Cox y Penáguila) o el suicido de cargos públicos ${ }^{40}$.

A principios de 1924, las promesas de interinidad de la Dictadura se fueron desvaneciendo. El Directorio Militar lo fundamentó en que todavía no había finalizado la labor de saneamiento político y administrativo que los "forzó" al poder. En febrero de 1924, el Gobernador de Alicante comunicaba a la Secretaría Militar del Directorio que "los políticos y caciques del antiguo régimen realizan en varios pueblos de la provincia labor contra el Directorio, estorbando el saneamiento iniciado por mí" "41. La realidad es que el Dictador no tenía intención de dejar el poder. La mediatizada política de fiscalización le había granjeado un importante respaldo social y la censura de prensa le permitía ocultar, de cara a la opinión pública, que muchos de aquellos investigados terminaron sin penas concretas. Poco a poco, el Directorio Militar se fue rodeando de un mayor número de asesores civiles ${ }^{42}$. Estos se encargaron de asesorar al Dictador en el establecimiento de una serie de medidas que aceleraron el paso de la fase inicial destructiva a la reorganizativa.

El 1 de enero de 1924 se ordenaba la disolución de los ayuntamientos constituidos por las Juntas de Asociados. Fue una consecuencia lógica ante el proyecto autoritario del régimen y frente a las numerosas irregularidades acaecidas en el seno de las Juntas de Asociados. Tradicionalmente, las Juntas de Asociados se conformaban de acuerdo a los intereses de los

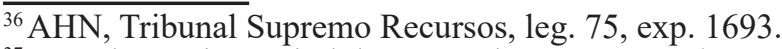

37 "RD de amnistía e indulto general", en Gaceta de Madrid, 18 de julio de 1924

38 "Los presos del Castillo. Han sido liberados ocho", en El Luchador, 3 de noviembre de 1923. La prensa progresista (dentro de los límites de la censura) criticó que se excarcelara antes a los delincuentes políticos que a los "procesados por conciencia": anarquistas, comunistas, sindicalistas etc.

${ }^{39}$ Muñoz Jofre, Jaume, La España ... op . cit., p. 48.

${ }^{40}$ Tenemos documentado el suicidio del alcalde de Bañeres (ADA, GE-16910-3) y el suicidio de Ricardo Alarcón, secretario de Guardamar. "Guardamar. Suicidio de otro secretario", en El Luchador, 22 de diciembre de 1923.

${ }^{41}$ AHN, Presidencia del Gobierno: Personal/Primo de Rivera. Leg. 343.

${ }^{42}$ Calvo Sotelo, José, Mis servicios ... op. cit., p. 25.
} 
caciques o prohombres del municipio. No es de extrañar las reiteradas denuncias hacia estos representantes o la disolución del nuevo ayuntamiento de Elche tras un escándalo político ${ }^{43}$.

La renovación decretada en enero y las siguientes hasta la aprobación del Estatuto Municipal dejó el nombramiento del nuevo personal municipal en manos de los delegados gubernativos. Eso garantizaba, a priori, una selección previa del personal por los brazos ejecutores del "saneamiento" a nivel comarcal. El Directorio establecía que el nuevo personal tenía que cumplir con una serie de principios: ser honrado, con un perfil técnico o profesional superior y con independencia de la política. Obviamente, en la capital fue posible cubrir los vacíos dejados por los viejos cuadros políticos (sobre todo con hombres de negocios, industriales y comerciales), pero a nivel provincial esa tarea se presentó arduo complicada. En muchas ocasiones el personal capacitado para ocupar los cargos fue escaso y cuando no, había participado en la vieja política ${ }^{44}$. Eso dio lugar a que se permitiera la participación de individuos con "tendencias liberales y conservadoras" y "labradores analfabetos" $"$. A mediados de 1924 fueron numerosos los telegramas que informaban sobre la gran influencia que continuaban ejerciendo a nivel local los caciques y políticos tradicionales. Lo cual nos permite reflexionar en torno al alcance que tuvo el proyecto regenerador del régimen.

La constitución de los nuevos ayuntamientos coincidió con el decreto de 12 de enero de disolución de las Diputaciones provinciales. Tradicionalmente, las Diputaciones habían sido utilizadas por los gobiernos de la Restauración como una pieza esencial en el entramado caciquil ${ }^{46}$. La posibilidad de que el gobernador designase libremente a los diputados provinciales permitió una renovación autentica de la Diputación ${ }^{47}$. La comparativa entre los diputados provinciales anteriores y posteriores al decreto de sustitución nos muestra una renovación total del personal político ${ }^{48}$. La gran mayoría de diputados, que no todos, nunca habían participado activamente en la política y provenían del mundo industrial y de los negocios. Este cambio se plasmó en la propia presidencia de la Diputación. Juan Grau Vilalta, sin militancia política conocida, comercial y presidente de la Cámara de Comercio, sustituyo a Jaime Llorca Lloret, político profesional y vinculado a la clientela de Ruiz Valarino. La Diputación de Alicante fue uno de los pocos entes que, una vez sustituido su personal, mejoró su gestión y atribuciones con las medidas introducidas por el Estatuto Municipal y provincial ${ }^{49}$.

\footnotetext{
${ }^{43}$ Pérez Ortiz, Juan Francisco, La Dictadura... op. cit., p. 183. Como demostró Álvarez Rey para las provincias andaluzas, la sustitución de los ayuntamientos por las juntas de asociados fue una medida ingenua que colocó en el poder a personas con la misma filiación que los concejales previamente destituidos. Álvarez Rey, Leandro y Encarnación Lemus López, Historia de Andalucía Contemporánea, Huelva, Universidad de Huelva, 1998, p. 370. ${ }_{44}^{44}$ Poveda Jover, Jonatan, "Discurso modernizador e infraestructura pública en la provincia de Alicante durante la dictadura primorriverista", en Revista de Historia, Transportes, Servicios y Telecomunicaciones, 33 (2017), p. 93. ${ }^{45}$ ADA, GE-16910-3.

${ }^{46}$ López Íñiguez, Julio, La Dictadura de Primo de Rivera en la provincia de Valencia. Instituciones y políticos, tesis doctoral, Universidad de Valencia, 2014, p. 471

${ }^{47}$ Forner Muñoz, Salvador, "La Dictadura..." op . cit., p. 199.

48 "Actas de la Diputación de Alicante”, ADA, GE-24499-1 y GE-24499-2.

${ }^{49}$ Poveda Jover, Jonatan, "Discurso..." op. cit., pp. 91-98.
} 
A inicios de 1924 quedó patente que la interinidad del régimen, la letra a noventa días, fue una promesa infundada. Aquel regeneracionismo ingenuo que se manifestó en una oleada de denuncias, acusaciones y sustituciones político-administrativas empezó a desvanecerse a principios de 1924. Entrado 1924, la fiebre anticaciquil y anticorruptiva fue frenada por el Dictador mediante un conjunto de Reales Órdenes ${ }^{50}$ que ponían de manifiesto, junto con una serie de cambios políticos y administrativos, la entrada en una fase de estabilización. Se iniciaban así una serie de movimientos destinados a crear y desarrollar nuevos instrumentos políticos sobre los cimientos de aquellos que habían dicho destruir. En abril se aprobaron un conjunto de medidas que demostraban que la dictadura estaba dispuesta a desarrollar una política propia. En aras de la institucionalización, se ordenó a los delegados gubernativos que redujesen la severidad en sus demarcaciones, al mismo tiempo que se aprobaba el Estatuto Municipal y trataba de crearse una justicia adicta ${ }^{51}$. Sin duda, una de las principales muestras del propósito institucionalizador de la Dictadura fue la creación, por mandato gubernativo, de la Unión Patriótica. Una especie de antipartido encargado de aglutinar a "gentes de ideas sanas y hombres de buena fe" ${ }^{52}$ que sirviesen de cantera política y administrativa del nuevo régimen.

Quedaba patente que aquella primera fase destructiva y fiscalizadora había llegado a su fin y se iniciaba una segunda fase mediante la organización de un proyecto perdurable que se hizo evidente con el paso al Directorio Civil. A lo largo de 1924 el régimen se percató de que no podía construir una alternativa política antiliberal sin contar con los grupos de poder tradicionales. Unos grupos que en mayor o menor medida habían participado del régimen anterior y que necesitaba incorporar (o al menos apaciguar) de cara al proyecto institucionalizador. Ello explica el decreto de amnistía e indulto general de julio de 1924 o que la gran mayoría de castigos penales fuesen temporales y de poca entidad. Se creó a partir de este momento una entente cordia $l^{53}$ entre los representantes de la Dictadura y una parte de los antiguos grupos de poder que satisfizo a ambas partes y permite comprender la paulatina trasferencia del antiguo personal político a la Dictadura. Las fuentes evidencian como a partir de la primavera de 1924 la prensa y las autoridades gubernativas relajaron, hasta ser meramente testimonial, su discurso anticorruptivo y las acusaciones directas a personalidades. A partir del segundo semestre de 1924, la preocupación del régimen viró hacia la denuncia de temas morales y cívicos.

\footnotetext{
${ }^{50}$ Cabrera, Mercedes y del Rey, Fernando, El poder de los empresarios: politica e intereses económicos en la España contemporánea (1875-2000), Madrid, Taurus, 2002, p. 208.

51 "La justicia municipal. La labor de la Junta Depuradora", en Las Provincias, 9 de agosto de 1924. Consúltese esta editorial para conocer los datos de los funcionarios de justicia alicantinos destituidos o suspendidos por la Junta Depuradora.

${ }^{52}$ Ordoñez Anula, Miguel Ángel, Dos siglos de bribones y algún malandrín. La corrupción en España desde el siglo XIX hasta la actualidad, Madrid, EDAF, 2014, p. 197.

${ }^{53}$ Muñoz Jofre, Jaume, La España... op. cit., p. 49.
} 


\section{El "nuevo" personal político de la Dictadura}

El objetivo de este epígrafe será analizar en qué medida se hizo efectivo el desmantelamiento de las antiguas estructuras de poder en la provincia de Alicante. Como hemos observado, el régimen llegó al poder con el objetivo de desterrar a la antigua clase dirigente e instituir una política "honesta". Trataremos, asimismo, de analizar si la pulcritud y honestidad preconizada por el régimen fue una línea roja o simplemente una bandera que enarboló en pos del respaldo social.

Una primera aproximación a los ayuntamientos constituidos a partir del Estatuto Municipal nos muestra que la reforma de la vida política local no fue abordada de manera sustancial por la Dictadura. En el ayuntamiento de Alicante y la Diputación fue posible reducir los grupos de influencia y contar con unos entes, prácticamente a lo largo de toda la Dictadura, con una mayoría de hombres nuevos o que habían participado en un segundo orden en la vida política regional. Esta primera aproximación nos muestra que la gran mayoría de representantes políticos en la capital provenían de la burguesía industrial, mercantil y profesiones liberales. También habrá presencia de conservadores, individuos ligados a los sectores católicos y mauristas, que verán en el régimen un trampolín para alcanzar una influencia política tradicionalmente copada por los liberales. Estas grandes corporaciones dispusieron, por su entidad, de un amplio sustrato social donde seleccionar a su personal y del control directo por parte de las autoridades gubernativas. La inexistencia del sufragio determinó que los representantes de los ayuntamientos y las diputaciones fueran aquellos que el régimen dispuso, permitiendo desmontar las reiteradas críticas de gobernación que señalaban las dificultades a las cuales se enfrentaba el régimen para evitar la entrada en los organismos provinciales de los antiguos grupos políticos.

Si hacemos un análisis de la filiación política de muchos de los individuos que integraron los ayuntamientos y otros entes provinciales, vemos como hasta 1925 destacaron los sectores independientes, con una limitada participación política o provenientes del catolicismo social. A partir de esa fecha aumentará de forma considerable lo que la prensa alicantina acuño como "camaleones políticos" ${ }^{54}$. Esta realidad se fundamentó en la propia estabilización del régimen y la búsqueda de una mayor participación ciudadana en aras de su institucionalización.

Se produjo de esta forma una entente satisfactoria para ambas grupos ${ }^{55}$, puesto que el régimen integraba a una parte de los antiguos políticos asegurándose la gobernabilidad ${ }^{56}$ (se evitó a políticos de primera fila y que hubiesen incurrido en algún escándalo) y estos, a su vez, veían garantizada la defensa de sus intereses. No es de extrañar que al poco de constituirse la

\footnotetext{
54 "Los camaleones. Cuando se cerraron los grifos", en El Día, 26 de febrero de 1930.

${ }^{55}$ Muñoz Jofre, Jaume, La España ... op. cit., p. 49.

${ }^{56}$ Muchos de los antiguos grupos de poder continuaban detentando una gran influencia en su territorio. La Dictadura no consiguió romper las redes de influencia en muchos municipios, optando por incorporarlos.
} 
Unión Patriótica se criticase la presencia en sus filas de oportunistas de los recién proscritos $\operatorname{partidos}^{57}$.

Son muchos los ejemplos de entrismo que existen para la provincia de Alicante. No debemos olvidar que la pertenencia a la Unión Patriótica era la plataforma necesaria para acceder a los cargos políticos y administrativos del territorio. Si en un principio habían destacado los mauristas y tradicionalistas, el cambio de actitud hacia los antiguos políticos hizo aumentar los esfuerzos de destacados hombres del partido liberal y conservador para ingresar en él y colaborar en las labores preparatorias de sucesión de la Dictadura ${ }^{58}$. Uno de los ejemplos más paradigmáticos será el de Alfonso de Rojas, cacique liberal de la ciudad de Alicante, el cual trató de afiliarse a la Unión Patriótica en 1924, y tras ser rechazado, volvió a intentarlo en 1928. En diciembre de 1925, en un momento de atonía general de la Unión Patriótica de Alicante, el Luchador $^{59}$ informaba sobre la vuelta del excacique Salvador Canals con el objetivo de hacerse cargo del comité local. Ninguna de estas dos figuras preeminentes terminó ingresando en la Unión Patriótica, tal vez su entrada hubiese supuesto una redistribución de los puestos de control político del partido o las reacciones contrarias de la prensa y los auténticos upetistas. Pero el freno a estos personajes de primera línea no supuso una restricción en la UP para los políticos de segundo orden.

Entre ellos, destacarían Antonio Girona Ortuño, jefe de la Unión Patriótica de Almoradí y diputado provincial en 1924, hijo de uno de los testaferros del Marqués de Rafal, participó en la vida política del Bajo Segura desde la Restauración hasta la II República ${ }^{60}$. Otro ejemplo será el del político ilicitano José Pascual Urbán. Católico tradicionalista, fue concejal conservador del ayuntamiento de Elche en 1918 y durante la Dictadura alternó su militancia en la UP con el cargo de Diputado Director del Hospital Provincial de Alicante. Uno de los casos más claros de la intrascendente política fiscalizadora de la Dictadura y el reciclaje de los antiguos políticos será el de Juan Carrió Pastor. Maurista, fue detenido en 1923 por un escándalo político en Orihuela; en 1926 la alcaldía oriolana lo nombra "secretario particular de la misma"61 y en 1927, aparecía como Vocal del Comité de la Unión Patriótica de Orihuela ${ }^{62}$.

En la primera línea de la política será más complicado rastrear la permanencia de políticos preeminentes del último quinquenio de la Restauración. Existen casos de individuos no vírgenes políticamente, pero creemos más razonable que su participación en los órganos políticos del régimen se debió o bien a las simpatías con el proyecto político de la Dictadura

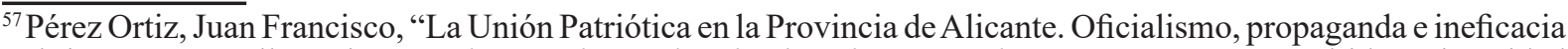
política", en Tusell, Javier et. al., Estudios sobre la derecha española contemporánea, Madrid, Universidad Nacional de Educación a Distancia, 1993, p. 367.

${ }^{58}$ Ibídem, p. 370.

59 “Canals, de la UP?”, en El Luchador, 29 de diciembre de 1925.

${ }^{60}$ Ferrández Pérez, Daniel, “Continuidad y sustitución clientelar durante la Segunda República desde una perspectiva a largo plazo. El caso de Almoradí (Alicante)", en Espacio, tiempo y forma. Serie V: Historia Contemporánea, 28 (2016), p. 173. DOI: 10.5944/etfv.28.2016.15770.

61 "Importantes Edictos en 4 a plana", en El Pueblo: semanario social y agrario, 26 de junio de 1926.

${ }^{62}$ AHN, Presidencia del Gobierno. Primo de Rivera, leg. 62.
} 
o a la continuidad en la defensa de sus intereses desde las nuevas estructuras de poder. Uno de los casos más significativos fue el del gobernador civil de Alicante durante 1928, Jiménez de Bentrosa. Este había estado afiliado al Partido Republicano, ejerció durante doce años el cargo de diputado provincial de Valencia y en 1920, durante el gobierno de Romanones, fue presidente de la Diputación valentina ${ }^{63}$. Sin una participación directa en la vida política previa, aunque vinculados a los grupos mauristas y católicos, destacan los prohombres Manuel Pérez Mirete y Pascual Más y Más. El primero de ellos, jurista y hombre de influencia en el territorio, fue Magistrado de la Audiencia de Alicante en 1924. En los años anteriores al golpe ejerció el cargo de Delegado de Hacienda ${ }^{64}$ y vinculado al Partido Conservador, terminó alejándose de él por la influencia del cacique Salvador Canals. Por su parte, Pascual Más, presidente de la Diputación de Alicante desde 1924 hasta 1929 y jefe provincial de la Unión Patriótica, fue un acaudalado industrial crevillentino, integrante del Sindicato Católico Agrario y con gran presencia pública en los años previos a la Dictadura.

En los pequeños ayuntamientos de la provincia es donde mejor se observa el transvase a la Dictadura de antiguos sectores políticos, la pervivencia de los grupos de poder y, en consecuencia, las limitaciones del proyecto de "renovación" política. Aunque es cierto que se produjo una renovación en una parte significativa del personal político, existieron comarcas y localidades donde la Dictadura toleró la pervivencia de ciertos individuos o grupos en aras de la gobernabilidad $^{65}$. Un caso muy significativo se dio en el partido judicial de Dolores (territorio con gran arraigo caciquil). En el verano de 1924, Enrique Albert, delegado gubernativo del partido, movido por las ansias regeneradoras, embestía contra los grupos de poder constituidos. En sus informes señalaba que ese partido judicial era la cuna del caciquismo, que no existía nadie (ni siquiera párrocos) independientes en política ${ }^{66}$. Según Enrique Albert, los jefes de los diversos bandos se habían mostrado neutrales al Directorio y dispuestos a ayudarle. El integrismo en el ejercicio de sus funciones y el ataque a estos grupos generó una serie de conflictos que motivaron su destitución. Las críticas a la pervivencia de sectores caciquiles se extendieron prácticamente hasta el final de la Dictadura. En febrero de 1925, el Gobernador Civil de Alicante advertía a gobernación que se dirigía a Madrid una comisión del ayuntamiento de Villena la cual estaba integrada por un cacique "quien promueve todos los disturbios" y que "probablemente tratará de sorprenderle a usted con falsos relatos" ${ }^{67}$. Una denuncia similar

\footnotetext{
${ }^{63}$ Poveda Jover, Jonatan, "Discurso..." op. cit., p. 92. Asimismo, Jiménez de Bentrosa había sido el primer gobernador civil de Navarra durante la Dictadura. Fuente Langas, Jesús María, La Dictadura de Primo de Rivera en Navarra, Pamplona, Gobierno de Navarra, 1998, p. 275.

64 “Gobierno Civil”, en El periódico para todos, 22 de agosto de 1919.

${ }^{65}$ Como ejemplos particulares tenemos a Rafael Pastor Barber, secretario del ayuntamiento de Bañeres, destituido por encontrarse procesado en 1923 (ADA, GE.16910-3), fue restituido en el cargo y aparece como secretario en 1929 (El Día, 23 de julio de 1929). Vicente Conca Blasco, concejal del Ayuntamiento de Benejama en 1922 y prestigioso industrial, ingresó en la UP y terminó ejerciendo de alcalde de la localidad. Antonio Roca de Togores, antiguo político y "fervoroso valarinista" (El Luchador, 17 de enero de 1923) fue vocal del comité oriolano de la UP y concejal en 1930.

${ }^{66}$ Pérez Ortiz, Juan Francisco, La Dictadura ... op. cit., p. 86.

${ }^{67}$ AHN, Ministerio de Gobernación, Serie A. leg. 37/1.
} 
efectuaba José Woldemar, upetista y ciudadano alemán residente en Alcoy, quien señalaba que en la Escuela Industrial de Alcoy seguía imperando un ambiente caciquil ${ }^{68}$.

La continuidad en la política local de antiguos grupos de influencia, la relajación gubernativa en el control de los ayuntamientos, la emergencia de nuevos grupos ávidos de poder $^{69}$ y el silencio impuesto por la censura de prensa, favoreció un ambiente de distensión en el cual proliferaron numerosas irregularidades y casos de corrupción. Para conocer las diversas irregularidades durante el septenio ha sido necesario recurrir a la documentación primaria, pues, el silencio de la prensa será total hasta 1930. En las siguientes líneas trataremos de exponer alguno de los casos más significativos que nos permiten poner en cuestión la integridad del discurso anticorruptivo y moralizador del régimen, en tanto en cuanto, fueron conocedores de los hechos y no aplicaron diligencias.

Una de las primeras irregularidades de las que tenemos constancia se dio a conocer al gobierno civil de Alicante en mayo de 1925 por parte del alcalde de Alcoy, José Beneyto. En un telegrama afirmaba no querer verse inmiscuido en las "negligencias" del Secretario de la corporación y presentaba su dimisión ${ }^{70}$. Un caso similar se producirá en el ayuntamiento de Alicante. En mayo de 1928, el gobernador civil de Alicante informaba al ministro de gobernación que debido a supuestas incompatibilidades (políticas) de los concejales del Ayuntamiento, el alcalde presentaba su dimisión. Señalando el gobernador: "negándome yo a admitirla. El asunto es largo, enojoso y muy complejo, incluso para carta"71. No hemos podido averiguar cuál fue "el asunto largo y enojoso", pero a la altura de 1928 resulta extraño que se debiera exclusivamente a una cuestión de incompatibilidades políticas. Poco después del decreto de incompatibilidades del 12 de octubre de 1923, el régimen había dejado claro que el apoyo y colaboración con la Dictadura suponía la no aplicación del decreto y la posibilidad de seguir realizando el trueque de servicios con la empresa ${ }^{72}$.

Las irregularidades políticas también tuvieron su correlato en el campo económico y empresarial. En 1924, el ayuntamiento de Alicante inauguraba la red de tranvías eléctricos de la ciudad. La empresa constructora y gestora del servicio fue Tranvías y Electricidad S.A, con una amplia participación accionarial del Banco de Vizcaya. El 28 diciembre de 1929, Venancio Echevarría, Director General del Banco de Vizcaya, escribía al alcalde de Alicante, Julio Suárez Llanos, para hacerle saber que la empresa no estaba teniendo los balances esperados, y que era necesario, para obtener rendimientos, que redujese el tránsito de sus competidores. El 31 de diciembre, incurriendo en un trato de favor, el alcalde hacía saber a Venancio Echevarría que

\footnotetext{
$\overline{{ }^{68} \mathrm{ADA}, \mathrm{GE}-16910 / 2 .}$

${ }^{69}$ La sustitución política impuesta por la Dictadura supuso, en algunos casos, el despegue de una nueva clase política dirigente que acaparó el poder y reprodujo los mismos mecanismos fraudulentos de "la vieja política".

${ }^{70}$ ADA, GE-16946-1. La dimisión no fue aceptada hasta julio de 1925.

${ }^{71}$ AHN, Ministerio de Gobernación, Serie A. leg. 37/2. Exp. 10.

${ }^{72}$ Alcalá Zamora, Niceto, Memorias, Barcelona, Planeta, 1977, pp. 102-103.
} 
había modificado, de acuerdo a sus intereses, los trayectos que debían cubrir las compañías concesionarias de autobuses ${ }^{73}$.

Fueron muchas las irregularidades político-administrativas cometidas durante la Dictadura. El régimen que llegó al poder con el objetivo de desterrar los vicios de la vieja política terminó reproduciendo a través de sus estructuras los mecanismos fraudulentos de la Restauración. La Dictadura no tuvo que recurrir a la manipulación electoral para ejercer su poder, se sirvió de un modelo de centralización política autoritaria, en el cual, los gobiernos civiles y sus intermediarios a nivel local ejercieron el poder sin oposición. Hemos señalado como estos grupos, muy débiles a nivel provincial, estuvieron compuestos por un contingente de individuos más preocupados en la defensa de sus intereses que en la identificación genuina con los preceptos del régimen. Ello explica los reiterados casos de abuso de poder, extralimitaciones y los choques de influencias entre diversos sectores. No fueron pocos los somatenistas que trataron de influir en la vida política local ${ }^{74}$ o los delegados gubernativos que, como Eduardo Llobregat Estany y Emilio Suau ${ }^{75}$, terminaron haciendo campaña política a favor de sus intereses ${ }^{76}$. Esto explica que a mediados de la Dictadura un sector de la sociedad advirtiera que los caciques se habían hecho con el control de la Unión Patriótica y los órganos de gobierno. Muchos de ellos no eran antiguos caciques ni provenían de la vieja clase política, sino que fueron hombres "nuevos" que reproducían viejas prácticas.

\section{Consideraciones finales: una revisión del regeneracionismo político}

A mediados de 1929 empezó a hacerse patente el agotamiento del régimen. La economía había entrado en una fase de decrecimiento que afectó a las clases populares, mientras que los sectores burgueses y acomodados, aquellos que habían aupado al Dictador, se distanciaban del régimen. La presión fiscal, el autoritarismo intervencionista y el fracaso en su proyecto de institucionalización creó un profundo descontento que se materializó en una oposición frontal al Dictador. A la altura de 1929, el Ejército y la Iglesia, sus principales grupos de apoyo, se alejaron de forma preventiva. La propia corona, inquieta por la ola de malestar y el evidente fracaso del régimen, terminó por darle la espalda. Carente de apoyos sociales y políticos, Primo de Rivera dimitía el 28 de enero de 1930.

\footnotetext{
$\overline{{ }^{73} \text { AMA, leg. 1918 }}-87-22 / 0$

${ }^{74}$ El cabo del Somatén de Benifallim fue amonestado por inmiscuirse en asuntos municipales, tuvo enfrentamientos con el alcalde y terminó siendo detenido (ADA, GE-16946-1).

${ }^{75}$ Emilio Suau fue uno de los poco delegados que se mantuvo en el cargo desde 1923 hasta 1929. Consiguió tejer una importante red de influencias y desarrollar una política personal que se materializó en un folleto denominado "Mejoras obtenidas en dos años de delegación gubernativa", en La Gaceta de Levante, 10 de agosto de 1926.

${ }^{76}$ Pérez Ortiz, Juan Francisco, La Dictadura... op. cit., pp. 100-102.
} 
La crítica sorda y disfrazada que desarrolló la prensa los últimos años de la Dictadura no hizo más que anteceder el estallido de las críticas directas a partir de la dimisión del Dictador y, en especial, tras la supresión de la censura de prensa en septiembre de 1930. La atención a los periódicos alicantinos a partir de abril de 1931 nos permite extraer una serie de valoraciones acerca del alcance de la política fiscalizadora del régimen.

Los militares llegaron al poder con la creencia mesiánica de la capacidad de transformación del país si este era guiado por hombres rectos y justos. Como argumentó Gómez-Navarro ${ }^{77}$, el régimen alcanzó el poder carente de una ideología clara. Ello motivó un regeneracionismo político inicial de carácter ingenuo que terminó frustrado ante una realidad que evidenciaba que los problemas del país eran más difíciles de solucionar de lo que creyeron los militares. Bajo este paraguas se desarrolló la transitoria política de fiscalización de las estructuras políticas, económicas y sociales del país. Un proyecto político que, basado en un propósito legitimador, consiguió atraer las simpatías de un importante sector de la sociedad alicantina. La política inicial del régimen se plasmó, en la provincia de Alicante, en una fiebre anticaciquil y anticorruptiva orientada a sanear la administración, desterrar a la antigua clase política y dar una imagen de firmeza y laboriosidad. A mediados de 1924, la política responsabilista comenzó a atenuarse coincidiendo con el inicio del proyecto estabilizador del régimen. Se precisaba de la connivencia y participación de los sectores más influyentes del territorio, unos sectores que en mayor o menor medida habían participado del régimen anterior. Ello explica la laxitud y brevedad de las condenas, el decreto de amnistía general y la tolerancia creciente de la Dictadura hacia la participación de los políticos provenientes del antiguo régimen.

Esta realidad nos permite preguntarnos en qué medida hubo una sustitución real del personal político de la Restauración y si se consiguió una reducción de los grupos de influencia territoriales. Como hemos observado, la "renovación" del personal político estuvo condicionada por diversos factos. Entre ellos, la institución o localidad de pertenencia. No supuso lo mismo, en cuanto al personal disponible y los mecanismos de control, renovar la plantilla política de la Diputación de Alicante o de la capital, que del conglomerado de municipios que componían sus comarcas. En este sentido, por lo que hace a la sustitución del personal político y, aplicando un análisis comparativo, podríamos señalar que la realidad política de la provincia de Alicante durante la Dictadura primorriverista estaría próxima al modelo valenciano y navarro ${ }^{78}$. Puesto que en el ayuntamiento de Alicante y la Diputación hubo una amplia renovación del personal político con individuos vinculados al mundo industrial, mercantil y técnico. Ello no determinó que fuesen vírgenes en la política, muchos provenían de sectores mauristas y católicos (alguno

\footnotetext{
${ }_{77}^{70}$ Gómez-Navarro, José Luis, El régimen ... op. cit., pp. 320-337.

${ }^{78}$ López Íñiguez, Julio, La Dictadura ... op. cit., pp. 321 y 478-479; Fuente Langas, Jesús María, La Dictadura ... op. cit., p. 177-188. El carácter industrial, mercantil y financiero de estas ciudades determinó la irrupción de una clase política marginada por la Restauración, pero ansiosa de cuotas de poder.
} 
fue un segunda fila de los partidos dinásticos), y otros, dada su preeminencia social, habían mantenido relaciones con los antiguos grupos de poder. Bien es cierto, no se observa en estos grandes entes la permanencia de antiguos políticos preeminentes, como sí se dio en gran parte de Andalucía ${ }^{79}$, ni un predominio notorio del militante "católico" (sobre el resto), como ocurrió en las comarcas castellonenses ${ }^{80}$. Aunque en Alicante los antiguos primeras filas quedaron relegados de los grandes entes, asistiendo a una reducción palatina de su influencia, no ocurrió lo mismo en gran parte de los núcleos rurales ${ }^{81}$. Por lo general, al igual que en el mundo rural valenciano y navarro, en las pequeñas localidades de la provincia, se produjo la pervivencia de antiguos políticos. La gran mayoría de ellos, prohombres del municipio, concebían la política como una herramienta en beneficio propio. Solo tenían que declarar que eran hombres de "buena voluntad" para integrarse en la administración dictatorial. Así, aunque se produjo la entrada de un importante número de hombres "nuevos", el régimen toleró, en aras de la gobernabilidad, a antiguos representantes políticos. En resumen, a pesar de los elogios del régimen, en la provincia de Alicante no se consiguió una desestructuración total de las antiguas relaciones de poder, ni se logró, de forma amplia, apartar a la antigua clase política.

Ello motivó la pervivencia de antiguos procedimientos delictivos. A pesar del discurso moralizador y anticorruptivo inicial de la Dictadura, esta no estuvo exenta de corrupción y procedimientos fraudulentos. Tras el primer año del régimen se fue gestando un ambiente propicio: se relajó la fiscalización política y la aplicación de la legislación anticorrupción, la censura de prensa silenció al principal agente fiscalizador de la contemporaneidad y la Dictadura, carente de una separación de poderes real y centrada en su institucionalización, toleró un ambiente de impunidad del cual se beneficiaron numerosos individuos. Habrá que esperar al cambio de régimen para conocer, a través de la prensa y la nueva administración, las corruptelas durante la Dictadura.

Iniciada la Segunda República se creó un ambiente responsabilista en el cual participó la nueva administración y la prensa. Fueron muchas las columnas que señalaron a presuntos corruptos, y varios los ayuntamientos que iniciaron comisiones de investigación. La más significativa, la "Comisión para la revisión de la vida municipal desde 1923" mayo de 1931 en el ayuntamiento de Alicante. En ella se señalaron múltiples irregularidades, siendo la más destacable la prevaricación de fondos públicos a favor de empresas concesionarias.

\footnotetext{
${ }^{79}$ Álvarez Rey, Leandro y Encarnación Lemus, Historia... op. cit., pp. 374-377. El carácter agrario y latifundista andaluz, junto con las fuertes estructuras clientelares herederas de la Restauración, determinaron un continuismo político durante la Dictadura.

${ }^{80}$ González Devís, Raül, "Católicos y autoritarios: la dictadura de Primo de Rivera en las comarcas castellonenses", en Navajas Zubeldía, Carlos y Diego Iturriaga Barco, Novísima. Actas del II Congreso Internacional de Historia de Nuestro Tiempo, Logroño, Universidad de la Rioja, 2010, pp. 235-244.

${ }^{81}$ La Vega Baja del Segura, uno de los bastiones del caciquismo alicantino, estuvo siempre bajo el control de los antiguos grupos de poder.

${ }^{82}$ AMA, leg. 1918-89-11/0
} 
A falta de un estudio más amplio, conocemos múltiples irregularidades de este tipo en la Casa de Socorro de Alicante, Hospital Provincial ${ }^{83}$, la empresa municipal de basuras etc. Lo cual permitiría abrir una futura línea de investigación para conocer los vínculos entre el personal político y las empresas beneficiarias de la política de obra pública de la Dictadura. Sin embargo, no faltaron casos de especial resonancia como la sustracción de 90.000 pesetas por parte de la dirección de la Cámara Pasera de Denia (organismo dependiente del Consejo de Economía Nacional) $)^{84}$.

La eclosión de este cumulo de escándalos al final de la Dictadura y la persistencia de la antigua clase política nos permite preguntarnos qué pasó con el espíritu regenerador y los procedimientos anticorruptivos de los primeros meses. La realidad es que fueron desarrollados deliberadamente para atacar al sistema de la Restauración y legitimar la puesta en marcha del nuevo régimen. Conseguido el respaldo social, aquellos hombres "de buena voluntad" reprodujeron los vicios de la vieja política mientras el régimen trataba de perpetuarse haciendo uso y silenciando todo aquello que había atacado.

\footnotetext{
83 "Dictamen de las obras del nuevo Hospital Provincial de Alicante". ADA, GE-18067/1.

84 "La Cámara Pasera ha sido disuelta”, en El Diario de Alicante, 25 de marzo de 1930.
} 